\title{
A CRIANÇA E O CANDOMBLÉ: considerações acerca de uma educação decolonial
}

\author{
Dalzira Maria Aparecida Iyagunã ${ }^{1}$ \\ Luis Thiago Freire Dantas ${ }^{2}$
}

\begin{abstract}
Resumo: As considerações deste artigo problematizam as perspectivas educacionais para a infância, tomando o Candomblé como fonte de aprendizagem. Se a ideia iluminista de "formação humana" continua sendo importante para a educação da criança, então propomos neste artigo ampliar o significado de "formação" para o envolvimento da espiritualidade na materialidade infantil. Com isso, há uma breve retomada das filosofias de Descartes e Rousseau para ilustrar a concepção ocidental e em seguida discutimos, no contexto de diáspora africana, noções de aprendizagem e educação para a infância no Candomblé. Tal proposta consiste na decolonização, caracterizada pelo envolvimento, acolhimento e africanidade. Uma decolonização que problematiza a noção de idade a partir da dinamicidade entre o tempo iniciático e o físico. Portanto, defendemos a ideia de "formação" pela aprendizagem contínua entre o adulto e a criança, o físico e o espiritual.
\end{abstract}

Palavras-chave: Candomblé. Decolonização. Educação para a infância.

\section{THE CHILD AND THE CANDOMBLÉ: considerations about a decolonial education}

Abstract: The considerations in this article problematize the educational perspectives for childhood, taking Candomblé as a source of learning. If the Enlightenment idea of "human formation" continues to be important for the education of the child, then we propose in this article to extend the meaning of "formation" for the involvement of spirituality in the child materiality. With this, there is a brief resumption of the philosophies of Descartes and Rousseau to illustrate the Western conception and next we discuss, in the context of the African diaspora, notions of learning and education for childhood in Candomblé. Such a proposal consists of decolonization, characterized by involvement, acceptance and Africanness. A decolonization that problematizes the notion of age from the dynamicity between initiatory and physical time. Therefore, we defend the idea of "formation" by the continuous learning between the adult and the child, the physical and the spiritual.

Keywords: Candomblé. Decolonization. Education for childhood.

\section{Introdução}

Na história ocidental da educação para a infância estabeleceu-se, desde seu início, a compreensão da criança como um ser incompleto. Tal incompletude seria o resultado de uma visão em que ora a criança seria dominada pelas vontades, ora seria um ser pueril e ingênuo. Assim, a educação pensada para a criança partiria de uma noção de des-envolvimento, para que ela se tornasse adulta, cujas principais características seriam o amplo exercício da razão e o controle das emoções. É na contramão dessa compreensão que neste texto proporemos uma perspectiva educacional decolonizadora, ou seja, que não apenas denuncia as amarras coloniais como também propõe outras formas de pensar e produzir conhecimento. Uma das formas é estabelecida pela noção de envolvimento da criança com o mundo físico e espiritual.

\footnotetext{
${ }^{1}$ Iyalorișá do Ile Așè Ojugbo Ògún. Doutoranda em Educação pela UFPR. Mestra em Tecnologia pela UTFPR. Bacharel em Relações Internacionais pela Uninter.

2 Doutor e Mestre em Filosofia pela UFPR. Especialista em Educação das Relações Étnico-Raciais NEAB/UFPR. Licenciado em Filosofia pela UFSE. Professor de Filosofia no IFES - Campus Linhares.
} 
Essa perspectiva está presente nas vivências em comunidade de religiões de matrizes africanas, como o Candomblé, pois nessa organização social religiosa a criança é vista, desde sempre, completa por manter contínuo diálogo entre a razão e a emoção.

A importância de tratar o Candomblé como fonte formativa para a criança é por entendermos que nessa dimensão religiosa a criança é um membro ativo da comunidade e com atribuições existenciais como em qualquer outra faixa etária. Ela se envolve e envolve o mundo à sua volta, o que nos leva a pensar sobre a noção de desenvolvimento, acionada constantemente para fundamentar princípios ocidentais de "civilização", como sendo "um objetivo a atingir, um caminho a prosseguir, um sonho para muitos povos." (AMARO, 2017, p. 80). Diferentemente dessa perspectiva, a proposta neste texto visa evidenciar o quanto a presença da criança na tradição do Candomblé é cara para a própria ritualização das experiências educacionais no terreiro.

Este artigo elabora suas considerações a partir de referenciais filosóficos e de fundamentos da dimensão religiosa. É um texto produzido sob olhares diferentes, já que parte da compreensão e experiência de mundo de uma iyalorișa ${ }^{3}$ e das primeiras noções de um abíyán ${ }^{4}$ acerca desta tradição. Nesse exercício, demonstra-se uma importante característica do Candomblé: a ligação dos mais novos, em especial da criança, com os mais velhos. É esta conexão, estabelecida pela noção circular de organização do mundo espiritual, que retroalimenta a ligação entre os viventes e os que estão por vir, entre o passado e o futuro, entre o ontem e o amanhã. É uma ligação dinâmica, pois envolve noções de saber, de conhecer, de aprender e de rememorar, tendo como pano de fundo compreensões muito próprias de hierarquia, tradição, oralidade e ancestralidade. (IYAGUNÃ, 2013).

Para tanto será retomado brevemente algumas das teorias-base da educação moderna acerca da infância, que de um lado enfatiza uma noção de progresso para a maior-idade e de outro destaca a "intimidade" entre docente-discente para um cultivo da cidadania republicana. Em seguida detalharemos a dinamicidade da concepção de infância no Candomblé para, enfim, caracterizar a ideia de envolvimento através das

\footnotetext{
${ }^{3}$ Zeladora do așè. Sempre que possível adotaremos, como propõe Stela Guedes Caputo (2015, nota de rodapé 4), a grafia das palavras em yorubá: "Fazemos essa opção reconhecendo a importância da oralidade na manutenção dessa língua, mas acreditando também na importância da divulgação de sua forma escrita como mais um elemento do rico conhecimento que circula nos terreiros. Há divergências entre os autores sobre essa prática. [...] Não é uma posição pétrea e poderemos proceder de outra forma quando acharmos indicado" (CAPUTO, 2015, p. 775).
}

4 “Aquele ou aquela que participa do terreiro, mas não é iniciado ou iniciada" (CAPUTO, 2015, p. 776). 
características de acolhimento e africanidade como exercício de uma educação decolonial.

\section{A noção relativa de infância}

Immanuel Kant, ao tratar da pedagogia, faz uso de uma definição que corrobora o espírito do seu tempo: "o homem é a única criatura que precisa ser educada. Por educação entende-se o cuidado de sua infância, a disciplina e a instrução com a formação" (2002, p. 11). Contudo, tal definição ultrapassou a própria época quando, em certo sentido, perguntamos sobre as expectativas da educação: o cuidado e a formação. E acompanham tais expectativas a noção de disciplina e de instrução. Para Kant a noção de cuidado refere-se às precauções que pais e mães devem ter perante às crianças para que elas não passem dos limites das regras morais estabelecidas. A formação teria função positiva quando houvesse uma instrução para a "cultura" e negativa quando produzisse coerção com o objetivo de corrigir os defeitos humanos (disciplina). A disciplina, assim, seria puramente "negativa" dentro da noção kantiana para a pedagogia, já que "impede ao homem desviar-se do seu destino da humanidade [...] transformando a animalidade em humanidade.” (KANT, 2000, p. 12). Assim, a questão inicial é: como sucedeu historicamente a constituição da pedagogia em uma forma disciplinar? Principalmente pela tarefa imbuída à disciplina como aquilo que domina $\mathrm{o}$ "mau na natureza infantil": o egoísmo e as inclinações sensíveis. (VANDEWALLE, 2004).

$\mathrm{Na}$ antiguidade Greco-Romana e no período Medieval, essa instrução estabelecia um cuidado com a alma para evitar desvios de conduta do indivíduo. E a partir do Renascimento, a educação passou a visar a formação de um cidadão republicano. A atuação política passou a ter importância por interrogar o indivíduo acerca de seu posicionamento no mundo com os outros e, por consequência, o cuidado não se limitou à alma, mas também ao corpo. Com essas mudanças, duas invenções simbolizaram a instauração da modernidade: a infância e a educação. A infância manifestaria o estágio humano da incompletude, requerendo um tutor, já que a criança não teria autonomia para falar e além de características, ou certos modos, para ser adulto: amadurecimento racional e controle das emoções. Por sua vez, a educação seria a arte de erigir e aperfeiçoar o humano pois, agregada aos ideais iluministas, ela certificaria o desenvolvimento e o progresso de uma menor-idade para uma maioridade. No alcance da maior-idade, o humano se tornaria sujeito e, como tal, se 
distanciaria da natureza por entendê-la como um mero objeto:

Só então poderemos dizer ter colocado nas mãos dos homens, como justo e fiel tutor, as suas próprias fortunas, estando o intelecto emancipado e, por assim dizer, liberto da menoridade; daí, como necessária, segue-se a reforma do estado da humanidade, bem como a ampliação do seu poder sobre a natureza (BACON, 2002, p. 297, grifos nossos).

Com isso, a junção infância e educação aconteceu pelo exercício de decompor a realidade que propiciou o des-envolvimento da criança diante do mundo. Tomamos como exemplo as filosofias de Descartes e de Rousseau pois, mesmo com diferenças conceituais, servem para compreender o projeto ocidental acerca da infância e das práticas educativas.

Se para Descartes o modelo de humano se daria a partir de alguém com consciência moral e capaz de organizar os sentimentos, já para Rousseau o humano se concretizaria na "intimidade" com o mundo exterior, ou seja, na capacidade de dialogar consigo mesmo e corresponder politicamente com as mudanças da realidade.

Esses dois modelos teriam como tarefa filosófico-pedagógica exercitar na criança a diferenciação acerca daquilo que era verdadeiro do que era falso. Descartes entendia que na infância o ser humano exerce a imaginação e as vontades, ao invés da razão. A infância, permeada pela sensibilidade, não cultivaria o raciocínio e produziria seres mágicos para habitar a realidade, refletindo uma incompletude do humano nessa etapa. Para lidar com isso, ele propõe abandonar a condição infantil e, com efeito, fazer da razão um instrumento para "desencantar o mundo". Caso contrário, o império dos sonhos e do medo reinaria e implicaria o fracasso do modelo de ser humano, projeto primordial da modernidade europeia.

Ao contrário, Rousseau percebia que a razão não seria suficiente para obter a verdade: a infância seria a condição essencial para o desenvolvimento da filosofia justamente por ser uma etapa humana ainda não corrompida pelas invenções sociais, pelas máscaras e pelo teatro social. Por isso o período até os quinze anos fundamentaria o adulto e seu principal instrumento seria a pedagogia que, consubstanciada à filosofia, exercitaria os costumes e o modo de ser infante.

A forma como ambos os filósofos interpretaram a infância exibe características

\footnotetext{
${ }^{5}$ Esse termo não é utilizado por Descartes, mas é uma alusão ao diagnóstico de Max Weber (1982) sobre o processo da racionalização do mundo.
} 
de períodos modernos: o Iluminismo e o Romantismo. Se no primeiro há o ideal de progresso, exercício da razão e estabelecimento do dever moral, no segundo há uma maleabilidade entre o sujeito e o objeto, em que a razão se expressaria através da natureza. Essa maleabilidade evidencia a compreensão sobre a criança enquanto ser pueril e ingênuo e, similar ao Iluminismo, necessitando de um adulto para conduzi-la à verdade. $\mathrm{O}$ caráter de pureza e ingenuidade perdura até atualmente quando se fala de criança e como também da necessidade de um tutor como alguém para conduzi-la. Além desses dois pontos, há um terceiro, o des-envolvimento, que conecta esses movimentos modernos nos nossos modelos educacionais. Essa compreensão estabelece que a criança deve se distanciar do caráter sobrenatural pois, caso permaneça, a sua fala não é legitimada.

Atentos a essa normatização, é importante expor uma oposição de tradições acerca da criança com o intuito de entender o protagonismo infantil no intermeio entre a imaginação e a racionalidade, o invisível e o visível, o sobrenatural e a natureza. A contraposição se dará entre a tradição europeia e a africana, já que cada uma das tradições organiza as suas respectivas sociedades conforme as suas noções de infância.

Na Europa, a organização social perpassou pelo estabelecimento da pedagogia. Esta teve o significado atual, a partir do século XVII, como sendo um conjunto de teorias e normas educativas para as crianças. Por isso a infância consolidou-se como um período decisivo para a constituição do humano. Uma das concepções pedagógicas influentes para os períodos posteriores foi a visão de Rousseau acerca da educação. Tal influência pode ser observada na gravura "Professora Republicana"6, de 1793, que salienta uma intimidade maternal entre professora e aluno, denotando um aconchego entre ambos pelo modo como os seios são representados, acionando um sentido quase edipiano entre os personagens. Com isso, a professora torna-se uma "mãe" que auxilia o aluno/filho para desenvolver as suas aptidões e concentra toda a responsabilidade da aprendizagem em si mesma. Essa responsabilidade é presente quando sugere a obrigação de um elo familiar com as crianças em um lugar estranho: a escola. Por consequência, situados nessa instituição, professora (que se torna "tia", com funções alusivas ao papel da mãe) e aluno (sobrinho/filho), são postos como participantes de um processo comum: ensino-aprendizagem. Sem essa comunhão impede-se a existência da educação.

\footnotetext{
6 Presente no artigo "O que é ser um bom professor?" do blog Filosofia e Cultura. Disponível em: https://filosofia.pro.br/wp-content/uploads/2016/09/105661-365x390.jpg. Acesso em: 25 fev. 2019.
} 
Já a tradição africana, foco proposto neste texto, apresenta outros significados pedagógicos, de forma que a aprendizagem não se restringe a ações de condução à fase adulta, mas se estabelece pelo ato de envolvimento. $\mathrm{O}$ modelo de envolvimento seria, por exemplo, a proposta educacional da filósofa Ivy Goduka (2000), no período pósapartheid sul-africano. Trata-se de um modelo decolonizador da educação que destaca a presença de valores espirituais enraizados em "epistemes africanas": "Eu reclamo o direito de usar minha voz indígena/Africana para falar do coração e dos corações dos mais velhos, ookhokho, de minha vila kwaManxeba, eHeshele, que são os guardiões desses saberes espirituais." (GODUKA, 2000, p. 64).

Esses valores elencados formam cinco princípios: i) Responsabilidade individual pela interioridade: destaca o cuidado consigo mesmo (comer, dedicar um tempo específico para o repouso, exercitar, repousar) antes do relacionamento com os outros de maneira que "conecta seu self interior e sua paz interior com o Grande Espírito, uQamata." (GODUKA, 2000, p. 74); ii) Responsabilidade coletiva em cuidar da mãe terra: compreensão de que a Natureza é o resultado da criação do grande espírito e os antepassados, atrelados a ela, nos transmitem a "sabedoria centrada na espiritualidade." (GODUKA, 2000, p. 74); iii) Inter-relação, inter-conexão $e$ interdependência entre os humanos e as criaturas vivas e não-vivas: nada existe isolado, tudo está relacionado ao outro visível ou invisível; iv) Identidades individuais e familiares não estão separadas do contexto sociocultural e espiritual: esse princípio enfatiza a identidade como relação entre certos números de crenças, padrões comuns de comportamento e práticas culturais. Com isso o Nome torna-se uma via importante para a produção da identidade: "meu nome indígena, Nomanulengo luQobo Iwam, me concede uma autêntica identidade cultural e indígena. Significa direitos (humanos). É enraizado no solo africano [...], que reflete a unidade humana, uma comunidade coletiva." (GODUKA, 2000, p. 79); v) A Natureza, as criaturas vivas e não-vivas são o fundamento da realidade espiritual: o entendimento de que as culturas e as tradições africanas constituem-se através da comunicação com as várias formas de espiritualidade.

Em contexto diaspórico essa comunicação ultrapassa o âmbito institucional por se tratar de vivência. No caso brasileiro, a população africana, oriunda em grande incidência dos grupos yorubás do atual Benin, Togo e Nigéria, teve seus princípios espirituais enraizados nas expressões religiosas, como é o caso do Candomblé. Se concordarmos com Muniz Sodré (2002) de que o Candomblé não se trata apenas de 
religião, mas também de uma filosofia, então a experiência de uma decolonização educacional na perspectiva afro-brasileira perpassa pelo terreiro. A importância do terreiro advém da reterritorialização da África na diáspora "através de um patrimônio simbólico consubstanciado no saber vinculado ao culto aos muitos deuses, à institucionalização das festas, das dramatizações dançadas e das formas musicais" (SODRÉ, 2002, p. 53). E por essa reterritorialização de uma África "qualitativa" que o terreiro no contexto brasileiro compõe um lugar de resistência que tem como objetivo uma produção de humanidade ao buscar o equilíbrio entre todos os componentes do espaço visível ou invisível.

Na presença desse equilíbrio, a criança, o idoso e os jovens no Candomblé têm a comunidade em primeiro lugar. Esta é a grande chave da real inclusão. Essas três fases em convívio contínuo dizem respeito ao cuidar que atende as necessidades da outra pessoa que compõe um todo. Diante dessa composição, a criança se sente segura, amada e respeitada pela comunidade. Assim, abre-se um contexto sociorreligioso em que cultura e educação estão presentes no cuidado das crianças e que se caracteriza não somente através do contato com os mais velhos conversando, cantando, ouvindo histórias, mas também pela aprendizagem que envolve noções de higiene corporal, de ecologia e de botânica. Além do que é com os mais velhos que aprendem a conhecer as ewés (folhas) seja pelo cheiro, pelo aspecto e seus valores. Inclusive aprende-se que são interligados através das ewés, pois há um princípio, kò si ewé kó si òrísá (sem folha não há orixá), de interação contínua com a força vital, o àșẹ. Em decorrência, há uma série de contribuições filosóficas que podem ser argumentadas a partir dessa formulação, principalmente, na relação do território com a espiritualidade infantil.

Inicialmente, velhos, jovens e crianças comunicam-se com o meio ambiente, minerais, vegetais e animais e, desde muito novos, aprendem que os valores são integrados, nada está separado:

Não vemos o 'espaço' do mundo, vivemos nosso campo visual; não vemos as cores de mundo, vivemos nosso espaço cromático. Sem dúvida nenhuma [...] estamos num mundo. No entanto, quando examinarmos mais de perto como chegamos a conhecer este mundo, descobrimos sempre que não podemos separar nossa história das ações - biológicas e sociais - a partir das quais ele aparece para nós. O mais óbvio e o mais próximo são sempre difíceis de perceber. (MATURANA; VARELA, 2001, p. 28).

Compartilhando seus mundos, as crianças sentem no velho o cuidado; o velho 
vê a criança como o futuro de sua existência que dará sequência aos seus legados. Assim as duas faixas etárias precisam de uma série de observações. Por isso a criança ao ingressar nas escolas traz toda sua bagagem cultural, ambiental, social, seus hábitos e costumes, culinária e afetos. O problema é que a construção da nossa sociedade não comporta essa diferença, já que a maioria das escolas não têm preparo para acolher essas crianças. No máximo, por vezes se inteiram dos saberes espirituais com os próprios estudantes. Por consequência, a comunidade escolar afasta a criança da comunidade do terreiro, pois provoca a desvalorização do próprio sagrado para reproduzir os valores impostos pela colonialidade/eurocentrismo:

\begin{abstract}
A bagagem de regularidades próprias do acoplamento de um grupo social é a sua tradição biológica e sua cultura. A tradição é ao mesmo tempo uma maneira de ver e agir, e também uma forma de ocultar. Toda tradição se baseia naquilo que uma história estrutural acumulou como óbvio, como regular, como estável, e a reflexão que permite ver óbvio só funciona com aquilo que perturba essa regularidade. (MATURANA; VARELA, 2001, p. 265).
\end{abstract}

De um lado, no terreiro, todos eram de sua família, seja consanguínea ou de ancestralidade - de àșe e de outro são expostas ao conflito civilizatório do individualismo. Ainda, na maioria das vezes, a criança já sabe seu òrísá, o que representa muito para essa criança, porém na escola frequentemente ela não é aceita por inteiro. Um fato recente ilustra como crianças vivenciadoras do Candomblé são atacas em seus direitos: em fevereiro de 2019, em uma escola da região norte da cidade de São Paulo, um estudante de 12 anos de uma escola estadual, recém-iniciado na tradição angola, foi suspenso da escola por trajar as vestes rituais do período pós-iniciático. As imagens das agressões verbais sofridas pelo garoto, que estava em sala de aula e perante aos demais estudantes, foram compartilhadas em redes sociais. No vídeo, a justificativa do estabelecimento de ensino foi de que ele não estava "respeitando as regras da escola”. Essa situação levanta uma série questões não somente acerca do despreparo da comunidade escolar perante o fato, mas também por causa das expressões e das falas que explicitavam o incômodo diante de uma criança trajada com tais vestimentas. Trata-se de apenas um dos inúmeros exemplos de racismo religioso reproduzidos de variadas formas, sejam perseguindo crianças, jovens e adultos por causa de suas vestimentas, seja diante de um currículo decolonial que apresenta as tradições africanas 
e a história e a cultura afro-brasileira ${ }^{7}$.

Com isso, o modo de vivência espiritual das crianças de tradições africanas é julgado e discriminado pelos olhos alheios, como se elas estivessem em oposição às normas de conduta social. Por efeito, a criança é influenciada a conviver com um corpo estranho, ignorando uma sua identidade e hierarquia característica aos terreiros de Candomblé ou, em outras palavras, negando os saberes ancestrais como um dos valores centrais de sua forma de existir no mundo do àșe.

Essa existência permanece conflituosa para a criança, pois entre a comunidade de Candomblé e o espaço escolar há um julgamento que preza pelo "tudo é nosso" e, assim como, uma omissão da sua religiosidade. Essa omissão acaba sendo um modo de sobrevivência mediante o racismo religioso (atenuado pelo uso da palavra bullying) que suscita piadas, chacotas de seus símbolos sagrados. Por isso, ao propor uma educação a partir dos terreiros de Candomblé, não significa mera inovação, mas enfatizar as diferenciações nas formas de acolher e, conjuntamente, de respeitar as personalidades infantis sejam elas mais calmas ou mais peraltas. Podemos dizer que ao contrário da tradição europeia destacando a necessidade de um des-envolvimento da criança para exercer aos poucos o seu ser adulto, em âmbito africano e diaspórico as crianças são ouvidas conforme suas necessidades e também de acordo com os òrísás que os regem. Uma regência que não requer uso farmacológico de ritalinas, mas se utiliza de chás, banhos, orikis (rezas) e diálogo recíproco. Com isso, há uma parceria entre adultos e crianças para entender o conjunto de assistências, inclusive pelo fato da criança ser um ser ritualístico.

\section{Envolvendo a criança na aprendizagem}

Existe um aforismo nagô que diz: iká ko dogbá (os dedos não são idênticos). Isso porque cada dedo contém uma potência que somente no conjunto da mão tornamse iguais. Dessa forma, podemos dizer que as crianças não são idênticas, pensam e

\footnotetext{
${ }^{7}$ São inúmeros casos que podemos aludir, mas entre aqueles de repercussão midiática podemos destacar: "No Rio de Janeiro, um estudante de 12 anos foi impedido de entrar na escola pública em que estudava por usar guias (colares) de candomblé". Disponível em: https://educacao.uol.com.br/noticias/2014/09/03/rj-aluno-e-impedido-de-frequentar-escola-com-guias-decandomble.htm; "Fixado em local compartilhado entre o CMEI e a Igreja Batista de Vitória, no Espírito Santo, a boneca Abayomi foi retirada pelo pastor João Brito, que na época afirmou que o objeto era símbolo de 'macumba por se originar de uma religião africana"'. Disponível em: https://www.gazetaonline.com.br/noticias/cidades/2017/09/mpes-investiga-polemica-de-painel-comboneca-africana-em-creche-1014100465.html. Acessados em: 26 fev. 2019.
} 
reagem de maneiras diferentes, mas se tornam iguais em conjunto. Um conjunto que Alain (Émile Chartier) define como povo-criança: "uma criança isolada é comumente polida diante de um homem que não conhece. Mas quando são reunidas crianças da mesma idade, os sentimentos fortes nessa multidão resultam de imitação e contágio." (ALAIN, 1978, p. 31). No entanto, as avaliações educacionais continuam dependentes se certas crianças podem ou não ter melhor desenvolvimento, amenizando o fator se algumas são introspectivas ou se outras são falantes. Essa dependência, em grande parte, deve-se ao caráter iluminista que impõe como objetivo final a formação de um cidadão autônomo e obediente à razão. Em decorrência, não se aprende a respeitar o tempo e o espaço da criança, principalmente pelo equívoco em associar personalidades extrovertidas à inteligência e a introversão a uma deficiência na aquisição de conhecimentos.

Desse modo, podemos dizer que os adultos precisam aprender com a infância, já que normalmente a trata como um passado acessado através da memória ou como uma recorrência que realça uma personalidade excêntrica e intransigente às normas sociais. A aprendizagem da infância é outra, pois há um respeito pela singularidade e uma atenção aos sonhos. Com essas características não se privilegia a visão em detrimento dos demais sentidos, mas estimula a interação entre eles para perceber a variação de mundos possíveis. Com isso é fundamental que as crianças possam ser elas mesmas através do próprio tempo sem acelerar o amadurecimento. E isso se articula a um acompanhamento em âmbito educacional que preza pela comunhão entre docente e discente:

[...] ensinar não é transferir conhecimentos, conteúdos nem formar é ação pela qual um sujeito criador dá forma, estilo ou alma a um corpo indeciso e acomodado. Não há docência sem discência, as duas se explicam e seus sujeitos, apesar das diferenças que os conotam, não se reduzem a condição de objetivo, um do outro. (FREIRE, 1999, p. 25).

Por esse modo, nem mesmo a religião deve retirar a criança de seu tempo, tendo o direito de viver, criar, brincar, pensar e escolher sua maneira de ser criança. Porém, na vivência escolar normalmente nos deparamos com colocações do tipo: "É uma pena! Este menino não quer saber de estudar!”. Tais colocações surgem pela falta de um diálogo que destacaria as interações sociais caracterizadas por uma teia de relações entre o divino e a natureza.

O projeto educacional deve superar as relações adultocêntricas, já que a 
experiência do acolhimento das crianças envolvem relações para além da colonialidade e num processo de afirmação ancestral. Os rituais das culturas e das religiões de matrizes africana rompem com as determinações acerca da imagem do outro e passam a vivenciar relações de sororidade, afeto e respeito. Tais vivências percebem os sujeitos crianças como atores e atrizes sociais. Inclusive no Siré Órìsà (roda, ou dança para evocação dos Órìsàs) “as crianças ao serem abraçadas pelas divindades africanas com sua energia ancestral, não deixa de ser reconhecida como um ser que tem liberdade e singularidade.” (PEREIRA; SANTIAGO; SOUZA, 2018, p. 320).

Outro aspecto da ritualização é a africanidade, que "diz respeito à cultura material e simbólica da diáspora africana, recriada e ressematizada em território africano e não-africano" (OLIVEIRA, 2014, p. 30). Com a africanidade, outras racionalidades são caras para o processo de transformação e de mudança calcada na valorização da cultura infantil e na solidariedade afetiva para toda a comunidade. Inclusive conforme argumenta Stela Caputo (2018, p. 44) "toda criança é respeitada e cuidada não só por sua família carnal, mas por toda comunidade, inclusive porque a família de santo amplia os laços de parentesco", em grande medida por causa da percepção de que as crianças não são inferiores aos adultos, mas cada um tem uma função que alimenta a comunidade, assim como afirma o ditado: "a mão de uma criança não consegue alcançar uma prateleira, a mão de um adulto não entra em uma cabaça." (CAPUTO, 2018, p. 44). Acrescentando que no terreiro não é a idade civil que determina a hierarquia, mas a idade de quando se iniciou naquela comunidade, isso inverte a lógica adultocêntrica, já que a participação de crianças, jovens e adultos tem a premissa de respeitar o tempo de iniciado e, por efeito, as hierarquias dos cargos. Caputo $(2015 ; 2018)$ ilustra essa aprendizagem em alguns relatos:

Anísio Moreira, de 4 anos, é mais velho do que sua mãe, Clarisse Mantuano, de 40. A idade iniciática, tanto como o cargo recebido, desestabiliza a condição etária no modo como a conhecemos. A idade iniciática é mais importante que a idade civil. Esse fundamento, a idade iniciática, proporciona uma vivência paradoxal do conceito de geração. Do lado de fora do terreiro, na relação com pessoas alheias ao candomblé, Anísio tem 'apenas' 4 anos. Dentro do terreiro e na relação com pessoas de terreiro, ainda que fora dos terreiros, ele também tem 4 anos, é protegido e cuidado. Respeita e obedece aos pais e aos mais velhos civilmente sem que isso o subalternize, mesmo que não tivesse um cargo. (CAPUTO, 2018, p. 43).

Essa diferença qualitativa entre o filho e mãe não são observadas pelo exterior, 
mas pela espiritualidade. Uma espiritualidade marcada pelo momento em que o orí (a cabeça), cabeça não somente como parte superior do corpo (orí òde), mas principalmente cabeça espiritual (orí inú). E que, conforme Wanderson Flor do Nascimento (2011, p. 139), representa o eu mais profundo: "É a cabeça que nos orienta. Essa orientação pela cabeça, pelo eu, se dá no meio da comunidade (Egbé). É nesta comunidade que a orientação, que poder ser entendida também como deslocamento, como um pôr-se a caminhar." Isso provoca um cuidado no campo físico da mãe pelo filho e, no espiritual, o cuidado do filho pela mãe. Por consequência, estabelece-se um processo de aprendizagem na comunhão com o outro. Em outro relato explicita-se o aprender mútuo:

O processo de aprendizado é narrado de forma semelhante por João Vitor, de 8 anos, iniciado no Candomblé desde os 4 anos. No terreiro, ele é Omo Oba Àsẹ João Vitor ti Airá. Ou seja, 'filho do rei de Àsẹ João Vitor de Airá'. Assim como Patrick, seu irmão de santo, ele aprende a língua cantando e rezando e, sobretudo, afirma com o Bàbá Daniel. Sempre chamado de Omorobá, João Vitor evidencia o mais importante elemento de aprendizado nos terreiros: 'Eu olho para as pessoas e aprendo, mas também ensino cantigas e ensino a tocar'. As trocas espalhadas nas redes educativas dos terreiros distribuem os conhecimentos. (CAPUTO, 2015, p. 780).

A distribuição de conhecimentos perfaz o círculo de envolvimento da criança com o terreiro. Um círculo atento às singularidades que permite um diálogo entre a cultura infantil e a adulta ou entre a do mais velho e a do mais novo. Não atento a isso, qualquer visão para as hierarquias do Candomblé é um convite ao equívoco ocidental de inferiorizar o dessemelhante. Por isso, a idade iniciática é superior à idade cronológica, pois conforme Caputo e Passos (2007, p. 97) "quando um adulto chega para começar a aprender a religião, uma criança já iniciada, pode perfeitamente ser responsabilizada para the passar os ensinamentos", acrescentando que existe um saber e uma experiência que desarruma certa hierarquia nos moldes ocidentais modernos, principalmente quando o assunto é a criança. Em grande medida é que na ordem espiritual a criança é o ancestral mais antigo que faz se presente e o ancião é o ancestral mais novo que passará para o espiritual. Essa diferença de posições proporciona outros modos de pensar a educação.

Um modo de pensar destacado nesse artigo é através da noção de envolvimento que, filosoficamente, implica um envolvimento circular da criança com aquilo que dialoga com a sua ancestralidade. Com esse diálogo, a produção de conhecimento situase na interação da criança com o adulto e vice-versa. Como o objeto do artigo foi o 
Candomblé, então a orientação da aprendizagem privilegiou o tempo como círculo do aprender e ensinar. Com essa percepção, a aprendizagem não se limitaria no conteúdo por também marcar o caráter ritualístico, pois a compreensão de um evento não se determina pela avaliação das competências e habilidades e sim pela temporalidade espiritual que a criança entende algumas das experiências comunitárias.

Isso pode ser exemplificado através do abíyán. Como não adentrou na fase iniciática, o saber da comunidade de terreiro permanece desconhecido. Porém, o desconhecimento não é uma falta: diz respeito à posição do abíyán diante do ritual. Tais digressões encaminham para uma pergunta filosófica da educação: como experimento aquele aprender? Esse como não decide o ser criança ou o ser adulto, mas é um questionamento que envolve a própria pessoa: até que ponto eu exerço o respeito diante daquela aprendizagem? Uma vez respondido, quem sabe é possível entender as práticas pedagógicas através de outros caminhos além daqueles determinados hegemonicamente. Tanto que a atividade de decolonizar a educação diante envolvimento da criança da diáspora africana situa-se entre o acolhimento e a africanidade. Cada um deles expõe uma ritualização do processo educacional sem recorrer a finalidades externas ao sujeito, mas entende a formação como uma aprendizagem contínua entre o adulto e a criança, o físico e o espiritual.

\section{Últimas palavras}

As reflexões apresentadas neste artigo pretenderam instigar outras perspectivas para pensarmos a educação para a infância. Tais perspectivas seriam alternativas às noções de infância que estabelecemos a partir das nossas expectativas pedagógicas. Isso é detalhado pela influência das ideias iluministas ainda presentes nos dias de hoje, entre as quais está a "formação humana". Tal ideia compõe um dos pilares da educação para a infância justamente por causa da exigência de desenvolvimento da criança para a sociabilidade adulta.

Para exemplificar essa ideia da "formação humana", tratamos das filosofias de Descartes e Rousseau. E, enfatizando a teoria de Rousseau, a compreensão sobre a profissão do docente ao público infantil demonstrou que está reservada ao gênero feminino uma direta associação à figura materna. Desse modo, a comunhão docente/discente apresenta-se como crucial para entrada da criança na maioridade. A problemática observada nessas concepções se concentra na necessidade de um tutor 
para acompanhar e desenvolver a criança. Tanto que o desenvolvimento trata-se de um eixo principal para a ideia de "formação humana". Inclusive na construção da palavra, o des- simboliza uma separação, negação ou afastamento e, dessa forma, a criança desenvolve retirando de si o caráter instintivo acerca do mundo para conhecer e dominar os possíveis medos.

Em resposta tratamos neste artigo de alternativas à noção de infância não estabilizada na verticalidade etária, mas através de uma idade dinâmica por movimentar-se no espaço físico e espiritual. Tal alternativa consistiu nas expressões filosóficas e religiosas do Candomblé, expressões que sinalizaram a importância da criança para os ritos do terreiro e no cultivo da comunidade. Dentro de tais concepções a criança precisa envolver-se com as necessidades da própria comunidade e, por efeito, o amadurecimento não se trata de um melhoramento, ou tipo de aperfeiçoamento, mas uma aprendizagem que permite dialogar com os espaços físicos e espirituais. E, portanto, esse diálogo parte da interação com o mundo em diversas perspectivas.

Recebido em: 28-02-2019 Aceito em: 11-03-2019

\section{REFERÊNCIAS}

ALAIN, Émile Chartier. Reflexões sobre a educação. São Paulo: Editora Saraiva, 1978.

AMARO, Rogério Roque. Desenvolvimento ou Pós-Desenvolvimento? DesEnvolvimento e... Noflay!. Cadernos de Estudos Africanos, Lisboa, v. 34, p. 75-111, 2017. Disponível em: https://journals.openedition.org/cea/2335\#text. Acesso em: 12 fev. 2019.

BACON, Francis. The New Organon and Related Writings. Ed. Fulton H. Anderson. New York: Macmillan Publishing Company, 1960.

CAPUTO, Stela Guedes. Aprendendo yorubá nas redes educativas dos terreiros: história, culturas africanas e enfrentamento da intolerância nas escolas. Revista Brasileira de Educação, Rio de Janeiro, v. 20, p. 773-775, jul-set, 2015. Disponível em: http://www.redalyc.org/articulo.oa?id=27540282010. Acesso em: 12 fev. 2019.

CAPUTO, Stela Guedes. Reparar miúdo, narrar kékeré: notas sobre nossa fotoetnopoética com crianças de terreiros. Revista Teias, Rio de Janeiro, v. 19, n. 53, p. 36-63, abr/jun, 2018. Imagens e sons para além das escolas. Disponível em: https://www.epublicacoes.uerj.br/index.php/revistateias/article/viewFile/34443/25360. Acesso em: 12 fev. 2019. 
CAPUTO, Stela Guedes; PASSOS, Mailsa. Cultura e conhecimento em terreiros de candomblé - lendo e conversando com Mãe Beata de Yemonjá. Currículo sem Fronteiras, v. 7, n. 2, p. 93-111, jul/dez 2007. Disponível em: https://www.curriculosemfronteiras.org/vol7iss2articles/caputo-passos.pdf. Acesso em: $12 / 02 / 2019$.

GODUKA, Ivy. African indigenous philosophies: legitimizing spiritually centred wisdoms within the academy. In: HIGGS, Paul et al. (Org.) African Voices in Education. Landswone: Juta \& Co. Ltd.

FLOR DO NASCIMENTO, Wanderson. Orí: a saga atlântica pela recuperação das identidades usurpadas. In: Edileuza Penha de Souza. (Org.). Negritude, Cinema e Educação. 1ed. Belo Horizonte: Mazza, v. 3, p. 134-146.

FREIRE, Paulo. Pedagogia da Autonomia: Saberes Necessários à Prática Educativa. São Paulo: Paz e Terra, 1999.

IYAGUNÃ, Dalzira Maria Aparecida. Templo Religioso, Natureza e os Avanços Tecnológicos: os saberes do Candomblé na Contemporaneidade. Dissertação (Mestrado) - Universidade Tecnológica da Federal do Paraná, Programa de PósGraduação em Tecnologia, 2013.

KANT, Immanuel. Sobre a pedagogia. Campinas: UNIMEP, 2002.

MATURANA, Humberto; VARELA, Francisco. A árvore do conhecimento: as bases biológicas da compreensão humana. São Paulo: Pala Athenas, 2001.

OLIVEIRA, Eduardo David de. Africanidades. In: SILVA, Cidinha da (Org.). Africanidades e Relações Étnico Raciais: Insumos para Políticas Públicas na Área do Livro, Leitura e Bibliotecas no Brasil. Brasília: Fundação Cultural, 2014.

PEREIRA, Artur Oriel; SANTIAGO, Flávio; SOUZA, Ellen Gonzaga de Lima. Ubuntu: acolhimento ancestral e inquietações feministas negras à educação de bebês e crianças pequenas em creches e pré-escolas. Revista Teias, Rio de Janeiro, v. 19, n. 53, p. 314-329, abr/jun, 2018. Disponível em: https://www.epublicacoes.uerj.br/index.php/revistateias/article/view/33547/25373. Acesso em: 12 fev. 2019.

SODRÉ, Muniz. O Terreiro e a Cidade: A forma social negro-brasileira. Rio de Janeiro: Imago Editora; Salvador: Fundação Cultural do Estado da Bahia, 2002.

SODRÉ, Muniz. A Verdade Seduzida: por um conceito de cultura no Brasil. Rio de Janeiro: DP\&A, 1983.

VANDEWALLE, Bernard. Kant: educacíon y crítica. Buenos Aires: Nueva Visíon, 2004.

WEBER, Max. A ciência como vocação. Ensaios de sociologia. Rio de Janeiro: Zahar, 1982. 
